Organic Chemistry and Biochemistry of the Czech Academy of Sciences, Prague, Czech Republic: Fluorescent Nanodiamonds Modified With Biocompatible Polymers

- Elena Kupcová, university teacher at Department of Chemistry of the Matej Bel University, Banská Bystrica, Slovakia: Sample Pre-Treatment and Determination of Polycyclic aromatic hydrocarbons Mixture in Different Types of Matrices

Klaudia Kvaková explains the theme of her research and poster: Sentinel node(s) (SN) mapping became the standard procedure used in cancer diagnostics. However, agents commonly used to map the nodes have several major drawbacks. Fluorescent nanodiamonds (FNDs) are biocompatible materials that exhibit unique optical properties enabling their visualization in biological systems and thus could replace the now commonly used agents. Here we focus on the preparation of FNDs labelled with D-mannose for SN visualisation. It has been also shown that these particles interact specifically with macrophages, which are retained in the lymphatic nodes providing their clear imaging contrast.

Elena Kupcová gives insight into the theme of her research and poster: Polycyclic aromatic hydrocarbons $(\mathrm{PAH})$ are very persistent organic contaminants found not only throughout the whole spectrum of environment such as soil or water, but are also carefully monitored in the food. The poster presents analytical methods applicable to the determination of $18 \mathrm{PAHs}$ in water, soil and meat samples; the data acquired by three extraction methods (Soxhlet extraction, solid-phase extraction, liquid-phase microextraction) and two chromatographic methods (high-performance liquid chromatography coupled with fluorescent and UV detection, gas chromatography coupled with mass spectrometry) are compared.

\section{The 53rd International Chemistry Olympiad in (Virtual) Japan}

\section{by Nobuhiro Kihara}

The International Chemistry Olympiad (IChO) is an annual competition for talented students who are interested in chemistry. Nations around the world send a delegation of up to four students at the secondary school level along with two pedagogically professional mentors. In a usual IChO, the participating students are tested on their chemistry knowledge and skills in a five-hour laboratory practical examination and a

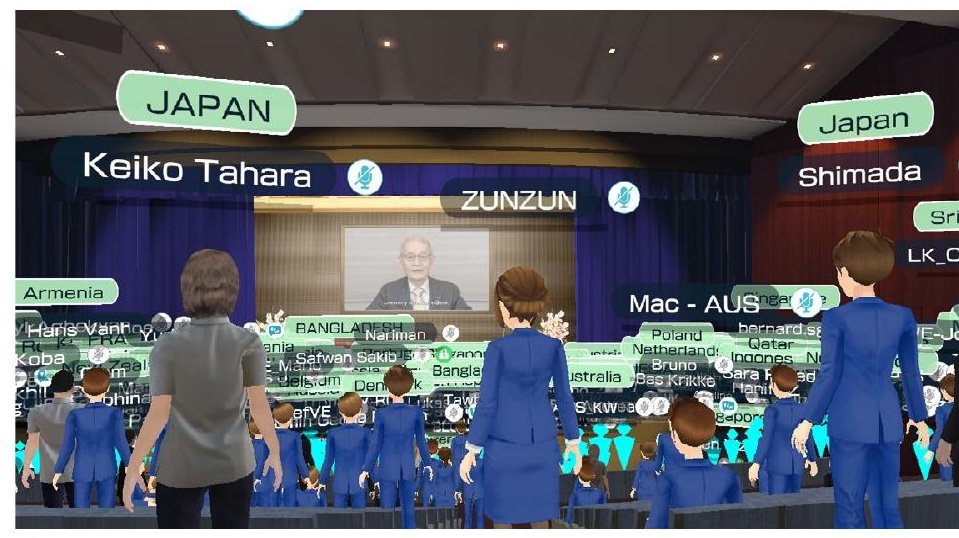

five-hour written theoretical examination.

The IChO program is intended to stimulate students' interest in chemistry through solving creative chemical problems that are both practical and theoretical. It also aims to promote international contacts in chemistry, friendships between young chemists of different nationalities, cooperation among pupils, and exchange of scientific experiences in chemistry. The first IChO was held in the former Czechoslovakia in 1968, and the event has been held every year since then. The delegations that attended the early events were mostly countries of the former Eastern Bloc, and the event was not held outside the Bloc until 1980 when it was held in Austria.

All participants are ranked according to their individual scores, and no official team scores are given. Gold medals are awarded to the top $10 \%$ of students, silver medals are awarded to the next $20 \%$ of students, and bronze medals are awarded to the next $30 \%$ of students. Honorable mentions are awarded to the top $10 \%$ of non-medalist students.

The IChO is composed of three key elements: Examination

Chemistry is an experiment-based science, with every theory coming out of the laboratory. Therefore, both theoretical and practical examinations play important roles in the IChO.

Japan held the 53rd IChO in July 2021. It was originally planned to follow the 2020 Olympic and Paralympic Games in Tokyo. We anticipated that popular interest in chemistry would be enhanced by a scientific Olympiad being held after the excitement of a sporting Olympiad. When we heard the first reports of COVID-19 early in 2020, it appeared to be a minor concern. Despite the virus being thought of as causing a new kind of cold, we knew that the common cold is inactive in summer when the IChO was to be held. However, shortly after the pandemic spread across the globe, it became evident that COVID-19 was active 
in summer, too. The 2020 Olympics and Paralympics were postponed for one year, and so was the IChO in Japan. Instead, in 2020, the 52nd IChO was held remotely for the first time and organized in Istanbul, Turkey <https://icho2020.tubitak.gov.tr/>

\section{Communication}

Talented students from all over the world come together to take part in the IChO. Conversation, cooperation, and communication with each other provide a great opportunity for promising youngsters to enjoy international experiences and to make friends with other participants via their common interest, chemistry. Culture

The venue chosen for the 53rd IChO, the Kansai area, is $500 \mathrm{~km}$ from Tokyo and was the ancient capital where according to Japanese legend, the first government of Japan was established 2681 years ago. Several places were to be visited, including not only very old temples but also state-of-the-art scientific institutes.

In the middle of January 2021, the Organizing Committee (OC) of the $53 \mathrm{rd}$ IChO met with the Steering Committee (SC) via Zoom. Two proposals were discussed: one for an in-person Olympiad and one for a remote event. Unfortunately, it was already clear that all the elements of the IChO described above could not be included in an in-person IChO during the COVID-19 pandemic, due to difficulties in travelling and the need for social distancing.

The first priority being of course the safety of all participants, it was ultimately decided to hold the 53rd IChO as a remote event. The SC approved a remote $\mathrm{IChO}$ at its second meeting at the end of February. In this remote IChO, the competition only involved theoretical problems, and the students attended the examination from their own countries. Most of the elements essential to the IChO would be lost in the remote IChO, which was very disappointing. Even in a remote format, however, the important features of IChO must be maintained as much as possible. The participating students must have extraordinary experiences. Therefore, the Organizing Committee incorporated several activities and communication tools into the 53rd IChO to cover these important features:

\section{Examination}

In order to reinforce the importance of laboratory work, the practical tasks prepared for the 53 rd IChO were made open, despite not being officially approved by the International Jury meeting for the 53rd IChO. The Organizing Committee prepared videos in which all tasks were demonstrated with explanations and published the videos as one of the activities during the event.

The OC would be delighted if those who are inspired by the demonstrations prepare and submit their original videos in which they attempt the practical tasks and discussions. Reports on the tasks will also be highly welcome.

\section{Communication}

OC prepared a virtual reality (VR) space for communication. When participants accessed the VR space, their avatars were created. Everyone could participate in events and activities via their avatars. In the VR space, there were venues in which avatars could enjoy close conversations, cooperation, and communication with others.

\section{Culture}

IChO participants were offered virtual visits to several locations, including Nara City, Osaka City, Kyoto City, and Himeji Castle. However, the OC added some that are very interesting to experience but not suitable for in-person visits due to hazards, sensitivity, space limitations, or language difficulties. SPring-8, a large synchrotron radiation facility that delivers the most powerful synchrotron radiation currently available, is one of the most interesting places in the Kansai area for the participating students of the IChO in particular. However, it is very difficult to visit SPring-8 as an activity in the IChO due to space limitations inside SPring-8 and the sensitivity of its advanced instruments. A workshop for preserving cultural assets, for example, repairing an image of Buddha, is another interesting place where modern chemistry is applied to very old subjects, although it is again very difficult to physically visit such a workshop because of the sensitive work, space limitations, and language difficulties. In the 53rd remote IChO, the participants virtually visited these highly restricted locations to experience more interesting cultural tours than would otherwise be possible.

The opening ceremony started at 15:00 JST on 25 July. The participants could access the ceremony via either the VR space or the usual video streaming. Over 200 participants entered the VR space to enjoy the realistic ceremony.

The first version of the theoretical problems was published at 21:00 JST on 25 July. It should be noted that 21:00 JST is almost the only time window to permit cooperation all over the world: 21:00 JST is 24:00 for the easternmost country, New Zealand, and 9:00 for the westernmost country, Costa Rica. Therefore, most of the programs were scheduled at 21:00 JST.

The OC sought comments on the problems from mentors, revised the problems according to the 
comments, then proposed a second version of the problems for finalization to the international jury meeting, the body that decides matters regarding the IChO that bind both participants and organizers. The jury meeting started at 21:00 JST on 26 July and finished around 2:00 JST on 27 July. The OC revised the problems according to the decisions of the jury meeting and published the official final version at 9:00 JST on 27 July. Next, the mentors started to translate the official English version into the individual local languages for their students. All delegations finished their translations by 9:00 JST on July 28 .

It should be noted that 60 hours elapsed from the publication of the first version of the problems to the deadline for translation. Of course, contact between mentors and students after the publication of the problems was clearly prohibited in the competition guidelines. If a mentor wanted to cheat, for example, passing on the problems and solutions to his or her students, we could not prevent it. However, the OC trusted in the professionalism and the pride of mentors. If a mentor had said to their students, "Hey, l'Il tell you the problems and solutions, then you'll all get gold medals," they would lose the respect of their students. As expected, there were no suspicious results in the scores obtained, confirming that the IChO community is strong and ethically healthy.

The translated versions of the problems were made available to the invigilators at 9:00 JST on 28 July. The invigilators downloaded and printed out the problems for the students by the starting time of the examination. The invigilators are a crucial component of the remote examination. The $O C$ asked country delegations to appoint invigilators who are independent of the mentors, have no relationship with students and have no other activity in the 53rd IChO. Invigilators were to be socially well-established persons such as school principals and should not be a parent or a relative of a student. For the same reason, the examination location should be a public place such as a school, and the $O C$ requested that each country choose a single location.

Unfortunately, restrictions on movement were severe in some countries during the period for the 53rd IChO. Further, some students had to quarantine because their close relatives were infected by COVID19. In such urgent circumstances, the OC allowed these students to take the examination in their homes, invigilated by their parents. The relevant delegations were asked to guarantee the fairness of the examination, and all delegations worked hard to make the students' homes suitable as examination locations.
A total of 309 students took the examination, while three students were absent. All examination locations were inspected beforehand via Zoom and were monitored and recorded throughout the examination via Zoom.

The earliest examination started at 12:00 JST on 28 July in New Zealand, the easternmost country, and the last examination started at 24:00 JST in USA and Costa Rica, the westernmost country. The examination time was 5 hours. Participating students were not allowed to use any communication devices or computers during the period 19:00 to 24:00 JST to avoid any ill-intentioned communication via the Internet or social media. All these requirements were controlled by the invigilators.

After the examination, the invigilators sorted the answer sheets by page numbers, scanned them to prepare PDF files for each student, and submitted them to the OC. After all answer sheets were received, the OC started marking.

After arbitration of the marking, the scores of all students were finalized, and the medals were allocated. The final results were announced in the closing ceremony at 21:00 JST, on 2 August, which was held also in VR and later published as a streaming video. Even after the closing ceremony, the participants could still enjoy virtual tours in VR.

After several events over the period of 11 days, the 53 rd IChO was successfully completed. The 53 rd IChO was financially supported by IUPAC, which we gratefully acknowledge. This support from IUPAC was used to subsidize participation fees for some countries that were facing economic difficulties. This year, there were several countries experiencing economic difficulties due to the COVID-19 pandemic.

At the end of this report, we wish to again congratulate all participating students. Some received medals, and some did not. However, they all tried their best to tackle the same chemical problems. When these youngsters meet again as the leaders in the field of chemistry, will they talk about the days of the 53rd IChO? We will be deeply honored if the 53rd IChO becomes one of the career milestones marked by the excellent chemists of the future.

Nobuhiro KIHARA was vice-chair of Executive Committee and vice-chair of Science Committee for ICh02021; he is professor at the Department of Chemistry at Kanagawa University, Japan 